Check for updates

Cite this: RSC Adv., 2018, 8, 13826

\title{
Synthesis, characterization and evaluation of bulky bis(pyrazolyl)palladium complexes in Suzuki- Miyaura cross-coupling reactions $\uparrow$
}

\begin{abstract}
Edward Ocansey, (iD) James Darkwa* and Banothile C. E. Makhubela iD *
Pyrazole-containing compounds have been used in recent times as ligands to stabilize metal complexes used as pre-catalysts in cross-coupling reactions. With various substituents at various positions in the pyrazole ring, the overall electrophilic and steric properties of the metal complexes can be fine-tuned. Herein, we report the synthesis of bulky pyrazole-based ligands by condensation of methyl 4(bromomethyl)benzoate or benzyl bromide with various substituted pyrazole compounds. These ligands were utilised in the synthesis of bis(pyrazolyl)palladium(॥) complexes. The complexes' catalytic activity in Suzuki-Miyaura cross-coupling reactions was evaluated. Phenyl bearing pre-catalyst 7, at a catalyst loading of 0.33 mol\%, successfully converted $98 \%$ of bromobenzene and phenylboronic acid to biphenyl in $4 \mathrm{~h}$ at $140{ }^{\circ} \mathrm{C}$, while the tertiary butyl bearing pre-catalyst 8 converted up to $81 \%$ of the same substrates to biphenyl. An increase in conversion was seen for all pre-catalysts when an electronwithdrawing substituent was present on the aryl halide substrate, and the opposite was observed when

the electron-withdrawing group was present on the phenyl boronic acid.
\end{abstract}

Received 14th February 2018

Accepted 26th March 2018

DOI: $10.1039 / c 8 r a 01430 b$

rsc.li/rsc-advances

\section{Introduction}

Synthesis of biaryl compounds, which are the building blocks for the preparation of the Merck and Novartis hypertensive drugs losartan and valsartan, involves the use of transition metal catalysts such as palladium and copper. ${ }^{1-5}$ Most notably, palladium complexes have gained widespread use as catalysts in both industry and academia for performing cross-coupling reactions mainly due to their thermal, oxidative and moisture stability, facile synthesis and the ability to modulate the steric and electronic properties of these palladium complexes. ${ }^{6}$ Bisligated palladium complexes, especially those with bulky monodentate ligands are well known for their anticancer properties $^{7,8}$ and as effective cross-coupling catalysts. ${ }^{9,10}$

Palladium catalysts coordinated in a trans fashion have been reported to demonstrate increased activity for cross-coupling between a wide array of aryl chlorides and amines at low catalyst loading, with a varied substrate scope. ${ }^{11}$ Similar observations have been made with the phosphine-ferrocenyl ligands reported by Štěpnička et al. ${ }^{12}$ Despite the extreme bulk of these ligands, they have insignificant distortion of the geometry around the metal from square planar as confirmed by X-ray

Department of Chemistry, University of Johannesburg, PO Box 524, Auckland Park, 2006, South Africa. E-mail: bmakhubela@uj.ac.za

$\dagger$ Electronic supplementary information (ESI) available: CCDC number 1555880 contains the supplementary crystallographic data for complex 7. For ESI and crystallographic data in CIF or other electronic format see DOI: $10.1039 / \mathrm{c} 8 \mathrm{ra0} 01430 \mathrm{~b}$ crystallography. Although these palladium complexes contain bulky ligands, they do not in any way affect the formation of the active $\operatorname{Pd}(0)$ species that are used in the Suzuki-Miyaura crosscoupling reactions. Bulky ligands, might, in fact, contribute to stabilization of the active $\operatorname{Pd}(0)$ species, and in spite of their steric bulk is able to isomerize to the cis conformation during the catalysis. ${ }^{12}$

The most popular ligand system in cross-coupling reactions are ligands that have phosphorus donor atoms. Phosphoruscontaining ligands facilitate the formation of bulky and electron rich complexes which allow for the effective cross-coupling of aryl halides and boronic acids. ${ }^{11}$ These ligands with phosphorus donor atoms have the ability to impart improved catalytic activity when used to form transition metal complexes. However, the drawback of phosphorus-containing ligands is their extreme sensitivity to air and moisture. Nitrogen donor ligands are providing alternatives to phosphorus donor ligands in that they can be tuned to obtain desired electronic and steric properties, in order to enhance the stability of the active $\operatorname{Pd}(0)$ species. ${ }^{13}$ An interesting class of nitrogen donor ligands are ligands that have pyrazolyl units. Pyrazolyl palladium complexes are ideal for cross-coupling reaction because the pyrazole nitrogen is a weaker $\sigma$-donor compared to imine and pyridines, and hence provides highly electrophilic metal centres. Additionally, the ability to vary substituents on the pyrazolyl ring allows the overall electrophilic and steric properties of resultant metal complexes to be adjusted. ${ }^{14-16}$ This is because the type of substituent affects the nucleophilicity of the nitrogen atoms in the ring and the bond strength of the 
subsequent ligated metal. Indeed several pyrazolyl palladium complexes have been used in recent times as pre-catalysts in cross-coupling reactions. ${ }^{10,17,18}$ Also with an increase in electrophilicity at the metal centre, the catalytic activity is enhanced. ${ }^{14,19,20}$ Mukherjee and Sarkar ${ }^{21}$ have demonstrated that pyrazolylimine palladium complexes have catalytic activities for Suzuki-Miyaura cross-coupling reaction that is dependent on the donor atoms and their steric environment. ${ }^{21}$ These pyrazolylimine ligands with low steric bulk and hard donor group such as $\mathrm{NMe}_{2}$ failed to catalyze the Suzuki-Miyaura crosscoupling reactions. This indicates that the ligands could not stabilize the $\operatorname{Pd}(0)$ species that is expected to catalyze the crosscoupling reaction. However, larger aryl groups on the imine nitrogen in the pyrazolylimine ligands were efficient catalysts for the Suzuki-Miyaura cross-coupling reaction. ${ }^{21}$

We herein report bis(pyrazolyl)palladium complexes with bulky substituents on the ligands and their applications as catalysts in the Suzuki-Miyaura cross-coupling reaction that clearly support how steric bulk of ligands enhance catalytic activities in cross-coupling reactions.

\section{Experimental}

\section{Materials}

All reactions were carried out in air unless otherwise stated. All solvents used were reagent grade, purchased from Sigma Aldrich and dried under nitrogen before use. 4-(Chloromethyl) benzoic acid, thionyl chloride, 1,3-diphenyl-1,3-propanedione, hydrazine monohydrate, sodium hydride, 2,2,6,6-tetramethyl3,5-heptanedione, potassium hydroxide, benzyl bromide, benzyl chloride, sodium hydroxide, sodium bicarbonate, potassium tert-butoxide, ethyl acetate and glacial acetic acid were purchased from Sigma Aldrich and used without further purification. $\mathrm{PdCl}_{2}$ was purchased from Heraeus South Africa and used as received. $\left[\mathrm{PdCl}_{2}(\mathrm{MeCN})_{2}\right],{ }^{22}$ 3,5-di-tert-butylpyrazole $^{23}$ 3,5-diphenylpyrazole ${ }^{24}$ and methyl-4-(chloromethyl) benzoate ${ }^{25}$ were synthesized according to literature procedures.

Synthesis of methyl 4-((3,5-diphenyl-1H-pyrazol-1-yl)methyl) benzoate (1). Into a round bottom flask containing $5 \mathrm{~mL}$ DMSO, $916.31 \mathrm{mg}$ (4.16 mmol) of 3,5-diphenyl- $H$-pyrazole was added and stirred for $5 \mathrm{~min} .363 .00 \mathrm{mg}(9.08 \mathrm{mmol})$ of $60 \% \mathrm{NaH}$ was then added and the mixture stirred at room temperature for 1 h. Thereafter, $700.00 \mathrm{mg}(3.79 \mathrm{mmol})$ of methyl-4(chloromethyl)benzoate was added and the resulting mixture stirred at room temperature for $3 \mathrm{~h}$. The contents of the round bottom flask were then transferred into $10 \mathrm{~mL}$ of distilled water. The mixture was then extracted with $4 \times 20 \mathrm{~mL}$ portions of diethyl ether. The organic layer was washed with $2 \times 5 \mathrm{~mL}$ distilled deionized water. The crude product was then purified by passing through a silica packed column and eluted with $1: 3$ diethylether : hexane mixture. The solvent was then removed by rotary evaporation followed by drying in vacuo for 6 hours to obtain the product. Appearance white solid (yield $=603.00 \mathrm{mg}$, $43 \%$ ). Solubility: soluble in chloroform, methanol, DCM, hexane and diethylether, insoluble in water. Melting point range $122-123{ }^{\circ} \mathrm{C}$. FT-IR $\left(\nu_{\max } / \mathrm{cm}^{-1}\right): 1712(\mathrm{C}=\mathrm{O}) .{ }^{1} \mathrm{H}$ NMR $(100$ $\left.\mathrm{MHz}, \mathrm{CDCl}_{3}, 30^{\circ} \mathrm{C}\right)(\mathrm{ppm})=7.95\left(\mathrm{~d}, 2 \mathrm{H}, J_{\mathrm{HH}}=8 \mathrm{~Hz}, \mathrm{H}_{\text {arom }}\right)$, $7.86\left(\mathrm{~d}, J_{\mathrm{HH}}=8 \mathrm{~Hz}, 2 \mathrm{H}, \mathrm{H}_{\text {arom }}\right), 7.42-7.31\left(\mathrm{~m}, 8 \mathrm{H}, \mathrm{H}_{\text {arom }}\right), 7.15$ $\left(\mathrm{d}, 2 \mathrm{H}, J_{\mathrm{HH}}=8 \mathrm{~Hz}, \mathrm{H}_{\text {arom }}\right), 6.67\left(\mathrm{~s}, 1 \mathrm{H}, \mathrm{H}_{\mathrm{pz}}\right), 5.42\left(\mathrm{~s}, 2 \mathrm{H}, \mathrm{H}_{\mathrm{CH}_{2}}\right)$, $3.87\left(\mathrm{~s}, 3 \mathrm{H}, \mathrm{H}_{\mathrm{CH}_{3}}\right) .{ }^{13} \mathrm{C}\left\{{ }^{1} \mathrm{H}\right\} \mathrm{NMR}\left(400 \mathrm{MHz}, \mathrm{CDCl}_{3}, 30{ }^{\circ} \mathrm{C}\right)(\mathrm{ppm})$ $=166.8 ; 151.3 ; 145.6 ; 142.8 ; 133.3 ; 130.5 ; 130.4 ; 130.2 ; 129.9$; 129.3; 128.8; 128.7; 127.8; 126.7; 125.7; 103.9; 53.0; 52.1; ESI-MS $[\mathrm{M}+\mathrm{H}]^{+}=369.16$. Elemental analysis; anal. calcd for $\mathrm{C}_{24} \mathrm{H}_{20} \mathrm{~N}_{2} \mathrm{O}_{2}$ : C, 78.24; 5.47; N, 7.60\%, found C, 78.42; H, 5.94; N, 7.31\%.

Synthesis of methyl 4-((3,5-di-tert-butyl-1H-pyrazol-1-yl) methyl)benzoate (2). Into a round bottom flask containing $5 \mathrm{~mL}$ DMSO, $750.00 \mathrm{mg}$ (4.16 mmol) of 3,5-di-tert-butyl- $1 \mathrm{H}^{-}$ pyrazole was added and stirred for $5 \mathrm{~min}$. $363.00 \mathrm{mg}(9.08$ $\mathrm{mmol}$ ) of $60 \% \mathrm{NaH}$ was added and the mixture stirred at room temperature for $1 \mathrm{~h}$. Thereafter, $700.00 \mathrm{mg}(3.79 \mathrm{mmol})$ of methyl-4-(chloromethyl)benzoate was added and the resulting mixture stirred at room temperature for $3 \mathrm{~h}$. The contents of the round bottom flask were then transferred into $10 \mathrm{~mL}$ of distilled water. The mixture was then extracted with $4 \times 20 \mathrm{~mL}$ portions of diethyl ether. The organic layer was washed with $2 \times 5 \mathrm{~mL}$ distilled deionized water. The crude product was then purified by passing through a silica packed column and eluted with $1: 3$ diethylether : hexane mixture. The first band was collected and identified as of methyl-4-(chloromethyl)benzoate after TLC comparison. The desired product eluted as the second band. The solvent was then removed by rotary evaporation followed by drying in vacuo for $6 \mathrm{~h}$ to obtain the product. (Yield $=501.22 \mathrm{mg}$, 40\%). Solubility: soluble in chloroform, methanol, DCM, hexane and diethyl ether, insoluble in water. Melting point range $138-139{ }^{\circ} \mathrm{C}$. FT-IR $\left(\nu_{\max } / \mathrm{cm}^{-1}\right)$ : $1713.12(\mathrm{C}=\mathrm{O}) .{ }^{1} \mathrm{H}$ NMR $\left(400 \mathrm{MHz}, \mathrm{CDCl}_{3}, 30{ }^{\circ} \mathrm{C}\right)(\mathrm{ppm})=7.90\left(\mathrm{~d}, 2 \mathrm{H}, J_{\mathrm{HH}}=8 \mathrm{~Hz}\right.$, $\left.\mathrm{H}_{\text {arom }}\right), 6.90\left(\mathrm{~d}, J_{\mathrm{HH}}=8 \mathrm{~Hz}, 2 \mathrm{H}, \mathrm{H}_{\text {arom }}\right), 5.92\left(\mathrm{~s}, 1 \mathrm{H}, \mathrm{H}_{\mathrm{pz}}\right), 5.49(\mathrm{~s}$, $\left.1 \mathrm{H}, \mathrm{H}_{\mathrm{CH}_{2}}\right), 3.86\left(\mathrm{~s}, 3 \mathrm{H}, \mathrm{H}_{\mathrm{CH}_{3}}\right), 1.29\left(\mathrm{~s}, 9 \mathrm{H}, \mathrm{H}_{t^{\mathrm{Bu}}}\right), 1.22\left(\mathrm{~s}, 9 \mathrm{H}, \mathrm{H}_{t^{\mathrm{Bu}}}\right)$. ${ }^{13} \mathrm{C}\left\{{ }^{1} \mathrm{H}\right\}$ NMR $\left(100 \mathrm{MHz}, \mathrm{CDCl}_{3}, 30{ }^{\circ} \mathrm{C}\right)(\mathrm{ppm})=166.8 ; 160.6$; 151.9; 144.6; 129.7; 129.6; 128.8; 125.8; 125.7; 100.3; 54.0; 51.9; 31.2; 30.1: ESI-MS $[\mathrm{M}+\mathrm{H}]^{+}=329.22$; elemental analysis; anal. calcd for $\mathrm{C}_{20} \mathrm{H}_{28} \mathrm{~N}_{2} \mathrm{O}_{2}: \mathrm{C}, 73.14 ; \mathrm{H}, 8.59 ; \mathrm{N}, 8.53 \%$, found $\mathrm{C}$, 73.22; H, 9.16; N, 7.85\%.

Synthesis of 1-benzyl-3,5-diphenyl-1H-pyrazole (3). Into a round bottom flask containing $20 \mathrm{~mL}$ acetonitrile, $51.170 \mathrm{mg}$ $(0.9120 \mathrm{mmol})$ of $\mathrm{KOH}$ was added and the mixture was stirred for $10 \mathrm{~min} .100 .00 \mathrm{mg}$ ( $0.45 \mathrm{mmol})$ of 3,5-diphenyl- $1 H$-pyrazole was added and the reaction mixture was stirred for an additional 20 minutes. Benzyl bromide $93.60 \mathrm{mg}(0.55 \mathrm{mmol})$ was then added slowly over an hour after which the reaction mixture was refluxed at $85{ }^{\circ} \mathrm{C}$ for $24 \mathrm{~h}$. A precipitate formed over time which was filtered off. The residue was collected and the solvent was removed by evaporation to give the crude product. The product was purified by passing through a silica packed column and eluted with $3: 7$ hexane : diethyl ether mixture. The second band was collected and identified as the product after TLC comparison with the starting materials. The solvent was then removed by rotary evaporation to obtain the product. Appearance; white crystals (yield $96.000 \mathrm{mg}, 68 \%$ ). Solubility: soluble in chloroform, DCM, and diethylether, insoluble in hexane, methanol and water. Melting point range $94-96^{\circ} \mathrm{C}$. FT-IR $\left(\nu_{\max } /\right.$ $\left.\mathrm{cm}^{-1}\right)$ : $1460(\mathrm{C}=\mathrm{N}) .{ }^{1} \mathrm{H} \mathrm{NMR}\left(400 \mathrm{MHz}, \mathrm{CDCl}_{3}, 30{ }^{\circ} \mathrm{C}\right)(\mathrm{ppm})=$ $7.71\left(\mathrm{~d},{ }^{3} \mathrm{~J}_{\mathrm{HH}}=7.2 \mathrm{~Hz}, 2 \mathrm{H}, \mathrm{H}_{\text {arom }}\right), 7.35-7.23\left(\mathrm{~m}, 11 \mathrm{H}, \mathrm{H}_{\text {arom }}\right)$, 
$7.03\left(\mathrm{~d},{ }^{3} \mathrm{~J}_{\mathrm{HH}}=6.8 \mathrm{~Hz}, 2 \mathrm{H}, \mathrm{H}_{\mathrm{arom}}\right), 6.58\left(\mathrm{~s}, 1 \mathrm{H}, \mathrm{H}_{\mathrm{pz}}\right), 5.31(\mathrm{~s}, 2 \mathrm{H}$, $\left.\mathrm{H}_{\mathrm{CH}_{2}}\right) .{ }^{13} \mathrm{C}\left\{{ }^{1} \mathrm{H}\right\}$ NMR $\left(100 \mathrm{MHz}, \mathrm{CDCl}_{3}, 30{ }^{\circ} \mathrm{C}\right)(\mathrm{ppm})=150.9$; $145.4 ; 137.7 ; 133.4 ; 130.6 ; 128.8 ; 128.7 ; 128.4 ; 128.3 ; 127.5$; $127.4 ; 126.9 ; 126.8 ; 126.7 ; 103.7 ; 53.2:$ ESI-MS $[\mathrm{M}+\mathrm{H}]^{+}=311.15$ (100\%). Elemental analysis; anal. calcd for $\mathrm{C}_{22} \mathrm{H}_{18} \mathrm{~N}_{2}$ : C, 85.13; $\mathrm{H}, 5.85 ; \mathrm{N}, 9.03 \%$, found C, 85.40; H, 5.65; N, 9.41\%.

Synthesis of 1-benzyl-3,5-di-tert-butyl-1H-pyrazole (4). Into a round bottom flask containing $20 \mathrm{~mL}$ acetonitrile, $62.500 \mathrm{mg}$ $(1.11 \mathrm{mmol})$ of $\mathrm{KOH}$ was added and the mixture was stirred for 10 minutes. $100.00 \mathrm{mg}(0.55 \mathrm{mmol})$ of 3,5-di-tert-butyl- $1 H$-pyrazole was added and the reaction mixture was stirred for an additional 20 minutes. Benzyl bromide $114.32 \mathrm{mg}(0.67 \mathrm{mmol})$ was added slowly over an hour, after which the reaction mixture was refluxed at $85{ }^{\circ} \mathrm{C}$ for $24 \mathrm{~h}$. A precipitate formed over time which was filtered off. The residue was collected and the solvent evaporated to give the crude product. The product was purified by passing through a silica packed column and eluted with $3: 7$ hexane : diethylether mixture. The second band was collected and identified as the product after TLC comparison with the starting materials. The solvent was then removed by rotary evaporation to obtain the product. Appearance; white crystals (yield $=110.10 \mathrm{mg}, 73 \%$ ). Solubility: soluble in chloroform, insoluble in water at room temperature. Solubility: soluble in chloroform, methanol, DCM, hexane and diethyl ether, insoluble in water. Melting point range $60-62{ }^{\circ} \mathrm{C}$. FT-IR $\left(\nu_{\max } / \mathrm{cm}^{-1}\right)$ : $1456(\mathrm{C}=\mathrm{N}) .{ }^{1} \mathrm{H}$ NMR $\left(400 \mathrm{MHz}, \mathrm{CDCl}_{3}, 30{ }^{\circ} \mathrm{C}\right)(\mathrm{ppm})=7.25$ $\left(\mathrm{t},{ }^{3} J_{\mathrm{HH}}=5.6 \mathrm{~Hz},{ }^{3} J_{\mathrm{HH}}=9.2 \mathrm{~Hz}, 3 \mathrm{H}, \mathrm{H}_{\mathrm{arom}}\right), 6.85\left(\mathrm{~d},{ }^{3} J_{\mathrm{HH}}=\right.$ $\left.7.2 \mathrm{~Hz} 2 \mathrm{H}, \mathrm{H}_{\text {arom }}\right), 5.89\left(\mathrm{~s}, 1 \mathrm{H}, \mathrm{H}_{\mathrm{pz}}\right), 5.45\left(\mathrm{~s}, 2 \mathrm{H}, \mathrm{H}_{\mathrm{CH}_{2}}\right), 1.29$ $\left(\mathrm{s}, 9 \mathrm{H}, \mathrm{H}_{t \mathrm{Bu}}\right), 1.23\left(\mathrm{~s}, 9 \mathrm{H}, \mathrm{H}^{t} \mathrm{Bu}\right) \cdot{ }^{13} \mathrm{C}\left\{{ }^{1} \mathrm{H}\right\} \mathrm{NMR}\left(100 \mathrm{MHz}, \mathrm{CDCl}_{3}\right.$, $\left.30{ }^{\circ} \mathrm{C}\right)(\mathrm{ppm})=160.3 ; 151.2 ; 139.2 ; 128.3 ; 128.1 ; 126.7 ; 126.5$; 125.8; 100.1; 54.1; 31.9; 30.3; ESI-MS $[\mathrm{M}+\mathrm{H}]^{+}=271.21$; elemental analysis; anal. calcd for $\mathrm{C}_{18} \mathrm{H}_{26} \mathrm{~N}_{2}$ : C, 79.95; $\mathrm{H}$, 9.69; N, 10.36\%, found C, 80.08; H, 9.34; N 10.14\%.

Synthesis of [\{bis(methyl 4-((3,5-diphenyl-1H-pyrazol-1-yl) methyl)benzoate)\}-palladium(II) chloride] (5). Into a Schlenk tube, $200.00 \mathrm{mg}$ of methyl 4-((3,5-diphenyl-1H-pyrazol-1-yl) methyl)benzoate $(0.54 \mathrm{mmol})$ was added to $70.417 \mathrm{mg}(0.27$ $\mathrm{mmol})$ of $\left[\mathrm{PdCl}_{2}(\mathrm{MeCN})_{2}\right]$ using $5 \mathrm{~mL}$ of DCM as solvent. The reaction mixture was then stirred for $24 \mathrm{~h}$ under argon at room temperature. The solvent was reduced in vacuo until the crude product began to precipitate. Hexane $5 \mathrm{~mL}$ was then added drop-wise until the product completely precipitated from solution. The precipitate was filtered off and washed with $2 \times 5 \mathrm{~mL}$ hexane and dried under vacuum for $6 \mathrm{~h}$ in order to obtain the product. Appearance yellow powder, (189.11 mg, 76\%). Solubility: partially soluble in chloroform, DCM, xylene and toluene, insoluble in methanol, water, hexane and diethyl ether. Melting point range $275{ }^{\circ} \mathrm{C}$ (decompose without melting). FT-IR $\left(\nu_{\max } /\right.$ $\left.\mathrm{cm}^{-1}\right)$ : $1713(\mathrm{C}=\mathrm{O}) .{ }^{1} \mathrm{H} \mathrm{NMR}\left(400 \mathrm{MHz}, \mathrm{CDCl}_{3}, 30^{\circ} \mathrm{C}\right)(\mathrm{ppm})=$ $8.15\left(\mathrm{~d}, J_{\mathrm{HH}}=6.8 \mathrm{~Hz}, 2 \mathrm{H}, \mathrm{H}_{\text {arom }}\right), 7.92\left(\mathrm{~d}, J_{\mathrm{HH}}=8 \mathrm{~Hz}, 2 \mathrm{H}, \mathrm{H}_{\text {arom }}\right)$, 7.33-7.28 (m, 6H, $\left.\mathrm{H}_{\text {arom }}\right), 6.99\left(\mathrm{~d}, J_{\mathrm{HH}}=5.6 \mathrm{~Hz}, 4 \mathrm{H}, \mathrm{H}_{\text {arom }}\right), 6.37$ $\left(\mathrm{s}, \mathrm{H}_{\mathrm{pz}}, 1 \mathrm{H}\right), 6.16\left(\mathrm{~s}, \mathrm{H}_{\mathrm{CH}_{2}}, 2 \mathrm{H}\right), 3.90\left(\mathrm{~s}, \mathrm{H}_{\mathrm{CH}_{3}}, 3 \mathrm{H}\right) ;{ }^{13} \mathrm{C}\left\{{ }^{1} \mathrm{H}\right\} \mathrm{NMR}$ $\left(100 \mathrm{MHz}, \mathrm{CDCl}_{3}, 30{ }^{\circ} \mathrm{C}\right)(\mathrm{ppm})=167.4,156.2 ; 149.9 ; 138.3$; $131.8 ; 129.4 ; 129.2 ; 128.9 ; 128.8 ; 128.7 ; 128.5 ; 128.4 ; 128.3$; 128.0; 127.9; 105.1; 57.1; 52.1; ESI-MS $[\mathrm{M}]^{+}=913.15$ (10\%); [M $\mathrm{Cl}]^{+}=878.18(5 \%) ;[\mathrm{M}-2 \mathrm{Cl}]^{+}=840.21$ (5\%); elemental analysis; anal. calcd for $\mathrm{C}_{48} \mathrm{H}_{40} \mathrm{Cl}_{2} \mathrm{~N}_{4} \mathrm{O}_{4} \mathrm{Pd}$ : C, 63.06; $\mathrm{H}, 4.41 ; \mathrm{N}$, $6.13 \%$ found $\mathrm{C}, 63.18 ; \mathrm{H} 4.71 \mathrm{~N}, 5.83 \%$.

Synthesis of [\{bis(methyl 4-((3,5-di-tert-butyl-1H-pyrazol-1yl)methyl)benzoate)\}-palladium(II) chloride] (6). Into a Schlenk tube, $200.00 \mathrm{mg}$ of methyl 4-((3,5-di-tert-butyl- $1 H$-pyrazol-1-yl) methyl)benzoate $(0.61 \mathrm{mmol})$ was added to $78.990 \mathrm{mg}$ (0.30 $\mathrm{mmol})$ of $\left[\mathrm{PdCl}_{2}(\mathrm{MeCN})_{2}\right]$ using $5 \mathrm{~mL}$ of DCM as solvent. The reaction mixture was then stirred for $24 \mathrm{~h}$ under argon at room temperature. The solvent was reduced in vacuo until the crude product began to precipitate. Hexane $5 \mathrm{~mL}$ was then added drop wise until the product completely precipitated from solution. The precipitate was filtered off and washed with $2 \times 5 \mathrm{~mL}$ hexane and dried under vacuum for $6 \mathrm{~h}$ in order to obtain the product. Appearance yellow powder, (184.24 mg, 73\%). Solubility: soluble in chloroform, DCM, partially soluble in xylene and toluene, insoluble in hexane, diethylether, water and methanol. Melting point range $241{ }^{\circ} \mathrm{C}$ (decomposed without melting). FT-IR $\left(\nu_{\max } / \mathrm{cm}^{-1}\right): 1716(\mathrm{C}=\mathrm{O}) .{ }^{1} \mathrm{H}$ NMR $(400 \mathrm{MHz}$, $\left.\mathrm{CDCl}_{3}, 30{ }^{\circ} \mathrm{C}\right)(\mathrm{ppm})=8.10\left(\mathrm{~d}, J_{\mathrm{HH}}=8 \mathrm{~Hz}, 2 \mathrm{H}, \mathrm{H}_{\text {arom }}\right), 8.05(\mathrm{~d}$, $\left.J_{\mathrm{HH}}=7.6 \mathrm{~Hz}, 2 \mathrm{H}, \mathrm{H}_{\text {arom }}\right), 7.21\left(\mathrm{~d}, J_{\mathrm{HH}}=8 \mathrm{~Hz}, 2 \mathrm{H}, \mathrm{H}_{\text {arom }}\right), 7.06(\mathrm{~d}$, $\left.J_{\mathrm{HH}}=8 \mathrm{~Hz}, 2 \mathrm{H}, \mathrm{H}_{\text {arom }}\right), 6.02\left(\mathrm{~m}, 6 \mathrm{H}, \mathrm{H}_{\mathrm{CH}_{2}}, \mathrm{H}_{\mathrm{pz}}\right), 3.93(\mathrm{~s}, 3 \mathrm{H}$, $\mathrm{H}_{\mathrm{CH}_{3}}$ ), $3.88\left(\mathrm{~s}, 3 \mathrm{H}, \mathrm{H}_{\mathrm{CH}_{3}}\right), 1.93\left(\mathrm{~s}, \mathrm{H}_{t_{\mathrm{Bu}}}, 6 \mathrm{H}\right), 1.89\left(\mathrm{~s}, \mathrm{H}_{t_{\mathrm{Bu}}}, 1 \mathrm{H}\right)$, $1.81\left(\mathrm{~s}, \mathrm{H}_{t_{\mathrm{Bu}}}, 6 \mathrm{H}\right), 1.61\left(\mathrm{~s}, \mathrm{H}_{t^{\mathrm{Bu}}}, 2 \mathrm{H}\right), 1.54\left(\mathrm{~s}, \mathrm{H}_{t_{\mathrm{Bu}}}, 3 \mathrm{H}\right), 1.29$ (s, $\left.\mathrm{H}_{t_{\mathrm{Bu}}}, 1 \mathrm{H}\right), 1.24\left(\mathrm{~s}, \mathrm{H}_{t_{\mathrm{Bu}}}, 7 \mathrm{H}\right), 1.22\left(\mathrm{~s}, \mathrm{H}_{t_{\mathrm{Bu}}}, 7 \mathrm{H}\right), 1.17\left(\mathrm{~s}, \mathrm{H}_{t_{\mathrm{Bu}}}, 3 \mathrm{H}\right)$, ${ }^{13} \mathrm{C}\left\{{ }^{1} \mathrm{H}\right\}$ NMR (100 MHz, $\left.\mathrm{CDCl}_{3}, 30{ }^{\circ} \mathrm{C}\right)(\mathrm{ppm})=167.3 ; 167.2$; $167.1 ; 167.0 ; 165.5 ; 160.9 ; 157.2 ; 153.4 ; 144.2 ; 141.9 ; 141.7$; $130.7 ; 130.6 ; 130.5 ; 130.3 ; 130.2 ; 130.1 ; 130.0 ; 129.9 ; 129.7$; 127.2; 126.9; 125.8; 105.4; 105.1; 56.6; 51.9; 33.0; 32.8; 32.3; 31.8; $31.7 ; 31.6 ; 31.5 ; 31.4 ; 31.3 ; 31.2 ; 30.5 ; 30.3 ; 29.9$; ESI-MS $[\mathrm{M}]^{+}=$ $835.28(40 \%)$. Elemental analysis; anal. calcd for $\mathrm{C}_{40} \mathrm{H}_{56} \mathrm{Cl}_{2} \mathrm{~N}_{4}$ $\mathrm{O}_{4} \mathrm{Pd}: \mathrm{C}, 57.59 ; \mathrm{H}, 6.77, \mathrm{~N}, 6.72 \%$ found $\mathrm{C}, 57.06 ; \mathrm{H}, 6.77 ; \mathrm{N}$, $6.69 \%$.

Synthesis of [\{bis(1-benzyl-3,5-diphenyl-1H-pyrazole $)\}$-palladium(II) chloride] (7). Into a Schlenk tube, $100.00 \mathrm{mg}$ of 1benzyl-3,5-diphenyl-1 $H$-pyrazole $(0.32 \mathrm{mmol})$ was added to $41.760 \mathrm{mg}(0.1609 \mathrm{mmol})$ of $\left[\mathrm{PdCl}_{2}(\mathrm{MeCN})_{2}\right]$ using $5 \mathrm{~mL}$ of DCM as solvent. The reaction mixture was then stirred for $24 \mathrm{~h}$ under argon at room temperature. The solvent was reduced in vacuo until the crude product began to precipitate. Diethylether $5 \mathrm{~mL}$ was then added drop wise until the product completely precipitated from solution. The precipitate was filtered off and washed with $2 \times 5 \mathrm{~mL}$ diethyl ether and dried under vacuum for $6 \mathrm{~h}$ in order to obtain the product. Appearance yellow powder, (71.211 mg, 55\%). Solubility: soluble in chloroform and DCM, partially soluble in xylene and toluene, insoluble in water, diethyl ether, methanol and hexane. Melting point range 250$251{ }^{\circ} \mathrm{C}$. FT-IR $\left(\nu_{\max } / \mathrm{cm}^{-1}\right): 1639(\mathrm{C}=\mathrm{N}) .{ }^{1} \mathrm{H}$ NMR $(400 \mathrm{MHz}$, $\left.\mathrm{CDCl}_{3}, 30{ }^{\circ} \mathrm{C}\right)(\mathrm{ppm})=8.20\left(\mathrm{~d}, J_{\mathrm{HH}}=7.2 \mathrm{~Hz}, 2 \mathrm{H}, \mathrm{H}_{\text {arom }}\right), 7.29-$ $7.13\left(\mathrm{~m}, 9 \mathrm{H}, \mathrm{H}_{\text {arom }}\right), 6.99\left(\mathrm{~d}, J_{\mathrm{HH}}=7.2 \mathrm{~Hz}, 2 \mathrm{H}, \mathrm{H}_{\text {arom }}\right), 6.94\left(\mathrm{t}, J_{\mathrm{HH}}\right.$ $\left.=8 \mathrm{~Hz}, J_{\mathrm{HH}}^{1}=7.6 \mathrm{~Hz}, 2 \mathrm{H}, \mathrm{H}_{\text {arom }}\right), 6.30\left(\mathrm{~s}, \mathrm{H}_{\mathrm{pz}}, 1 \mathrm{H}\right), 6.10\left(\mathrm{~s}, \mathrm{H}_{\mathrm{CH}_{2}}\right.$, $2 \mathrm{H}) ;{ }^{13} \mathrm{C}\left\{{ }^{1} \mathrm{H}\right\}$ NMR $\left(100 \mathrm{MHz}, \mathrm{CDCl}_{3}, 30{ }^{\circ} \mathrm{C}\right)(\mathrm{ppm})=155.3$; $149.1 ; 137.3 ; 131.0 ; 129.1 ; 129.0 ; 128.9 ; 128.8 ; 128.7 ; 128.6$; $128.5 ; 128.4 ; 128.3 ; 128.2 ; 110.1 ; 56.4$; ESI-MS $[\mathrm{M}+\mathrm{Na}]^{+}=823.12$ $(50 \%) ;[\mathrm{M}-\mathrm{Cl}]^{+}=765.17(50 \%) ;[\mathrm{M}-2 \mathrm{Cl}]^{+}=725.18(5 \%)$ elemental analysis; anal. calcd for $\mathrm{C}_{44} \mathrm{H}_{36} \mathrm{Cl}_{2} \mathrm{~N}_{4} \mathrm{Pd}$ : C, 66.22; $\mathrm{H}$, 4.55, N, 7.02\% found C, 66.46; H, 4.51; N, 6.78\%. 
Synthesis of $[\{$ bis(1-benzyl-3,5-di-tert-butyl-1H-pyrazole) $\}$ palladium(II) chloride] (8). Into a Schlenk tube, $100.00 \mathrm{mg}$ of 1benzyl-3,5-di-tert-butyl- $1 \mathrm{H}$-pyrazole $(0.3700 \mathrm{mmol})$ was added to $48.00 \mathrm{mg}(0.1850 \mathrm{mmol})$ of $\left[\mathrm{PdCl}_{2}(\mathrm{MeCN})_{2}\right]$ using $5 \mathrm{~mL}$ of DCM as solvent. The reaction mixture was then stirred for $24 \mathrm{~h}$ under argon at room temperature. The solvent was reduced in vacuo until the crude product began to precipitate. Hexane $5 \mathrm{~mL}$ was then added drop-wise until the product completely precipitated from solution. The precipitate was filtered off and washed with $2 \times 5 \mathrm{~mL}$ hexane and dried under vacuum for 6 hours in order to obtain the product. Appearance yellow powder, $(76.441 \mathrm{mg}$, $58 \%)$. Solubility: soluble in DCM, partially soluble in diethylether, xylene and toluene, insoluble in hexane, water and methanol. Melting point range $222{ }^{\circ} \mathrm{C}$ (decomposed without melting). FT-IR $\left(\nu_{\max } / \mathrm{cm}^{-1}\right): 1536(\mathrm{C}=\mathrm{N}) .{ }^{1} \mathrm{H}$ NMR $(100 \mathrm{MHz}$, $\left.\mathrm{CDCl}_{3}, 30{ }^{\circ} \mathrm{C}\right)(\mathrm{ppm})=7.4-7.2\left(\mathrm{~m}, 6 \mathrm{H}, \mathrm{H}_{\text {arom }}\right), 7.04\left(\mathrm{~d}, J_{\mathrm{HH}}=\right.$ $\left.4.8 \mathrm{~Hz}, 4 \mathrm{H}, \mathrm{H}_{\text {arom }}\right), 6.00\left(\mathrm{~m}, 6 \mathrm{H}, \mathrm{H}_{\mathrm{pz}}, \mathrm{H}_{\mathrm{CH}_{2}}\right), 1.94\left(\mathrm{~s}, \mathrm{H}_{t_{\mathrm{Bu}}}, 7 \mathrm{H}\right)$, $1.91\left(\mathrm{~s}, \mathrm{H}_{t_{\mathrm{Bu}}}, 2 \mathrm{H}\right), 1.83\left(\mathrm{~s}, \mathrm{H}_{t_{\mathrm{Bu}}}, 9 \mathrm{H}\right), 1.69\left(\mathrm{~s}, \mathrm{H}_{t_{\mathrm{Bu}}}, 2 \mathrm{H}\right), 1.26(\mathrm{~d}$, $\left.J_{\mathrm{HH}}=14.4 \mathrm{~Hz}, \mathrm{H}_{t_{\mathrm{Bu}}}, 7 \mathrm{H}\right), 1.19\left(\mathrm{~d}, J_{\mathrm{HH}}=6 \mathrm{~Hz}, \mathrm{H}_{t_{\mathrm{Bu}}}, 7 \mathrm{H}\right), 1.18(\mathrm{~s}$, $\left.\mathrm{H}_{t_{\mathrm{Bu}}}, 2 \mathrm{H}\right), 0.86\left(\mathrm{~s}, \mathrm{H}_{t_{\mathrm{Bu}}}, 2 \mathrm{H}\right) .{ }^{13} \mathrm{C}\{1 \mathrm{H}\}$ NMR $\left(100 \mathrm{MHz}, \mathrm{CDCl}_{3}, 30\right.$ $\left.{ }^{\circ} \mathrm{C}\right)(\mathrm{ppm})=164.1 ; 164.0 ; 157.0 ; 156.9 ; 135.8 ; 135.6 ; 129.0 ; 128.8$; $128.6 ; 128.2 ; 128.1 ; 127.9 ; 127.0 ; 126.8 ; 125.8 ; 105.2 ; 105.1$; 105.0; 55.9; 55.7; 33.0; 32.9; 30.5; 30.3; ESI-MS $[\mathrm{M}]^{+}=719.27$ (100\%); elemental analysis; anal. calcd for $\mathrm{C}_{36} \mathrm{H}_{52} \mathrm{Cl}_{2} \mathrm{~N}_{4} \mathrm{Pd}$ : C, $60.21 ; \mathrm{H}, 7.30, \mathrm{~N}, 7.80 \%$ found $\mathrm{C}, 60.35 ; \mathrm{H}, 7.60 ; \mathrm{N}, 7.70 \%$.

\section{Characterization of compounds}

NMR spectra was obtained using Bruker-400 MHz NMR spectrometer $\left({ }^{1} \mathrm{H}\right.$ at $400 \mathrm{MHz}$ and ${ }^{13} \mathrm{C}\left\{{ }^{1} \mathrm{H}\right\}$ at $\left.100 \mathrm{MHz}\right)$. Spectrometer chemical shifts were reported relative to the internal standard tetramethylsilane $(\delta 0.00 \mathrm{ppm})$ and referenced to the residual proton and carbon signals at 7.24 and $77.0 \mathrm{ppm}$ respectively of $\mathrm{CDCl}_{3}$. Infrared spectra were obtained neat using a Perkin Elmer Spectrum BX II fitted with an ATR probe. Melting points were obtained using a Gallenkamp Digital Melting-point Apparatus 5A 6797. Elemental analysis was performed on a Thermos Scientific FLASH 2000 CHNS-O Analyzer. Mass spectrometry was performed using Waters Synapt G2 mass spectrometer with both ESI positive and cone voltage $15 \mathrm{~V}$. XRD spectra were obtained from a Bruker APEX-II CCD Diffractometer. Analytical thin layer chromatography (TLC) was performed on silica gel coated aluminium plates $(0.2 \mathrm{~mm})$. Developed plates were visualized with UV light or under iodine staining. Silica gel column chromatography was performed using silica gel 60 (70-230 mesh).

\section{General experimental description of Suzuki cross-coupling reaction}

The Suzuki-Miyaura cross-coupling reaction was performed using a Radleys Carousel 12 Plus Reaction Station ${ }^{\mathrm{TM}}$ using $24 \times$ $150 \mathrm{~mm}$ quick-thread glass reaction tubes. The general procedure involved charging the reaction vessel with required amounts of aryl halide, boronic acid, base, internal standard ( $n$ decane) and solvent. A sample of the reaction mixture in the reaction vessel was taken at time zero and analyzed by GC to determine the ratios of various components. The required catalyst amount (catalyst loading in mol\%) was then added and the reaction left to proceed with a stir rate of $600 \mathrm{rpm}$. After reaction time had elapsed, aryl halide conversion to biphenyl was calculated by analyzing retention peak areas of aryl halide with reference to internal standard $n$-decane. GC analyses were performed using a Scion $456 \mathrm{GC}$ with $30 \mathrm{~m} \times 0.25 \mathrm{~mm}$ cyanopropylphenylmethylpolysiloxane phase column set to an initial temperature of $80{ }^{\circ} \mathrm{C}$ and then increased to $300{ }^{\circ} \mathrm{C}$ at $10{ }^{\circ} \mathrm{C} \mathrm{min}^{-1}$.

\section{Results and discussion}

\section{Synthesis and characterization of pyrazolyl ligands (1-4)}

Compounds 1-4 were synthesized in a substitution reaction involving substituted pyrazoles with the respective benzylic halides in the presence of excess base (Scheme 1). These compounds were obtained in moderate to good yields. The substitution reactions could readily occur at room temperature using DMSO, DMF or acetonitrile as solvents. The compounds display excellent solubility in organic solvents such as chloroform and DCM. They were extracted from either DMSO or DMF aqueous mixtures using diethyl ether. The substituted pyrazolyl ligands were characterized by ${ }^{1} \mathrm{H}$ NMR spectroscopy, mass spectrometry, elemental analysis and infrared spectroscopy. Downfield shifts in the ${ }^{1} \mathrm{H}$ NMR signals of the benzylic $\mathrm{CH}_{2}$ linker protons from around $4.50 \mathrm{ppm}$ to around $5.50 \mathrm{ppm}$ was observed indicating successful formation of the ligands. Further evidence for the synthesis of these ligands was confirmed via mass spectrometry and elemental analysis.

\section{Synthesis and characterization of bis(pyrazolyl)palladium(II) complexes (5-8)}

Complexes 5-8 were obtained by reacting the appropriate ligands in a $2: 1$ ratio with $\left[\mathrm{PdCl}_{2}(\mathrm{MeCN})_{2}\right]$ in DCM at room temperature for $24 \mathrm{~h}$. Over the course of the reaction, the resulting complexes 6, 7 and 8 remained soluble in DCM while 5 formed a yellow colloidal suspension. For all the complexes, the reaction mixtures were concentrated in vacuo and $n$-hexane or diethyl ether was added to the concentrated solution to encourage precipitation. The precipitates were obtained as varying shades of yellow solids in moderate to good yields. The complexes were also soluble in organic solvents such as DCM and chloroform. Characterization of these complexes by ${ }^{1} \mathrm{H}$ NMR spectroscopy showed a shift in the benzylic $\left(\mathrm{CH}_{2}\right)$ protons from around 5.40-5.50 ppm in the ligands to around 6.00$6.10 \mathrm{ppm}$ in the complexes. This was as a result of coordination of the pyrazolyl nitrogen atoms to the palladium, resulting in a reduced electron density around the $\mathrm{CH}_{2}$ protons. Mass spectra for all the complexes also confirmed their synthesis by showing the $\mathrm{m} / \mathrm{z}$ of the molecular ion peak or fragmentation patterns corresponding to the loss of chloride ions or gain of sodium ions.

\section{Molecular structure of compound 7}

The solid state structure of complex 7 was obtained using single-crystal X-ray diffraction. Crystals for complex 7 were 


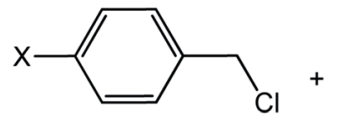

$\mathrm{X}=\mathrm{H}$ or $-\mathrm{COOCH}_{3}$<smiles>[R]c1cc([R])[nH]n1</smiles>

$\mathrm{R}^{1}={ }^{\mathrm{t}} \mathrm{Bu}, \mathrm{R}^{2}={ }^{\mathrm{t}} \mathrm{Bu}$

$\mathrm{R}^{1}=\mathrm{Ph}, \mathrm{R}^{2}=\mathrm{Ph}$

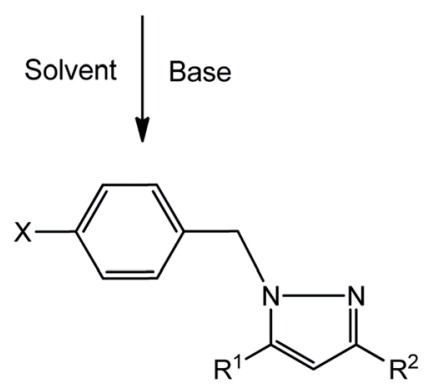

1: $R^{1}=P h, R^{2}=P h, X=-\mathrm{COOCH}_{3}$

2: $R^{1}={ }^{t} \mathrm{Bu}, \mathrm{R}^{2}={ }^{\mathrm{t}} \mathrm{Bu}, \mathrm{X}=-\mathrm{COOCH}_{3}$

3: $R^{1}=P h, R^{2}=P h, X=H$

4: $R^{1}={ }^{t} \mathrm{Bu}, \mathrm{R}^{2}={ }^{\mathrm{t}} \mathrm{Bu}, \mathrm{X}=\mathrm{H}$

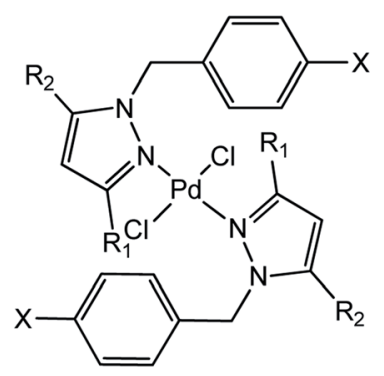

5: $\mathrm{R}^{1}=\mathrm{Ph}, \mathrm{R}^{2}=\mathrm{Ph}, \mathrm{X}=-\mathrm{COOCH}_{3}$

6: $R^{1}={ }^{t} \mathrm{Bu}, \mathrm{R}^{2}={ }^{\mathrm{t}} \mathrm{Bu}, \mathrm{X}=-\mathrm{COOCH}_{3}$

7: $\mathrm{R}^{1}=\mathrm{Ph}, \mathrm{R}^{2}=\mathrm{Ph}, X=\mathrm{H}$

8: $R^{1}={ }^{t} B u, R^{2}={ }^{t} B u, X=H$

Scheme 1 Synthesis of pyrazolyl ligands and complexes.

grown by slow evaporation of a DCM solution of 7 at room temperature and were obtained as yellow crystals. Complex 7 crystallized in a $P 1$ space group with a distorted square planar geometry at the palladium centre. The pyrazolyl ligands coordinated to the palladium in a trans fashion (Fig. 1). The bond angles around the $\mathrm{Pd}$ are between $89.61(4)^{\circ}$ and $90.39(4)^{\circ}$ which is in agreement of a square planar geometry. The crystal data and structure refinement parameters for 7 are presented in Table 1 . With only a slight distortion at the palladium centre, ${ }^{1} \mathrm{H}$ NMR spectrum for 7 showed that all phenyl protons on the pyrazole ring resided in the same chemical environments. Pd$\mathrm{N}_{\mathrm{pz}}$ and $\mathrm{Pd}-\mathrm{Cl}$ bond lengths as well as bond angles around the palladium centre for 7 were within reported ranges for similar bis(pyrazolyl)palladium complexes in literature. ${ }^{10}$

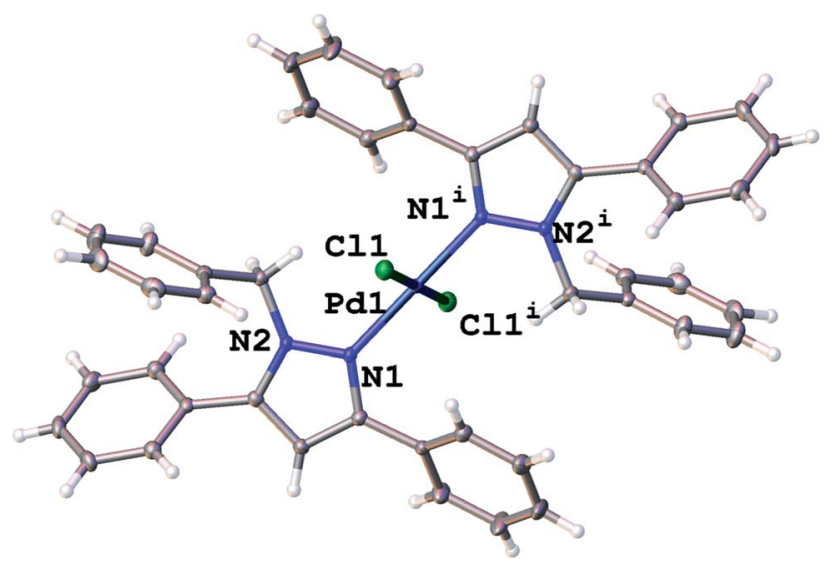

Fig. 1 Molecular structure of 7. Selected bond distance $(\AA)$ and bond angles $\left({ }^{\circ}\right) ; \operatorname{Pd}(1)-C l(1)$ 2.2924(4), $\operatorname{Pd}(1)-N(1)$ 2.0135(15), $N(2)-N(1)$ 1.363(2); $\mathrm{N}(1)-\mathrm{Pd}(1)-\mathrm{Cl}(1)$ 90.39(4), N(1)-Pd(1)-Cl(1') 89.61(4).

\section{Catalytic studies}

Evaluation of complexes 5-8 as pre-catalysts in SuzukiMiyaura cross-coupling reactions. Complexes 5, 6, 7 and 8 were screened as pre-catalysts for the Suzuki-Miyaura cross-coupling reactions. The cross-coupling reactions was performed using phenyl boronic acid ( $8 \mathrm{mmol})$, and bromobenzene $(5 \mathrm{mmol})$ as model substrates. At $0.066 \mathrm{~mol} \%$ catalyst loading, preliminary studies indicated the cross-coupling reaction was complete after $4 \mathrm{~h}$ (Table SI- $1 \dagger$ ). Increasing the reaction temperature resulted in a gradual increase in conversion. Beyond $140{ }^{\circ} \mathrm{C}$, there was a decrease in conversion for all four pre-catalysts. This was possibly as a result of the decomposition of the catalysts at high temperatures (Table SI-2†). Using strong inorganic bases like $\mathrm{KOH}, \mathrm{K}_{2} \mathrm{CO}_{3}$ and $\mathrm{Na}_{2} \mathrm{CO}_{3}$ resulted in high conversions for all 4 pre-catalysts. This may be as a result of the faster rate at which the phenyl borate species is formed. Using the weak organic base, triethylamine, resulted in poor conversions for all four pre-catalysts (Table SI-3†). Increasing the catalyst loading also resulted in increased conversions as expected (Table SI-4 $\dagger$ ). At $0.33 \mathrm{~mol} \%$ catalyst loading, using $\mathrm{KOH}$ as a base, $140{ }^{\circ} \mathrm{C}$ and $4 \mathrm{~h}$ reaction time, $98 \%$ conversion was achieved by $5,86 \%$ conversion for $\mathbf{6}, 98 \%$ conversion for 7 and $81 \%$ conversion for 8. Reducing the reaction time to $3 \mathrm{~h}$ or reducing the temperature to $130{ }^{\circ} \mathrm{C}$ under these conditions resulted in reduced conversions (Table SI-0 $\dagger$ ). In order to confirm the stereoelectronic effects of the substitutents on the pyrazolyl ring, dichlorido bis-(1H-pyrazole)palladium(II) was synthesized according to literature procedure ${ }^{26}$ and evaluated as a catalyst precursor in the Suzuki-Miyaura cross-coupling using phenylboronic acid and bromobenzene as coupling partners. Evaluation of dichlorido bis-( $1 \mathrm{H}$-pyrazole)palladium(II) in SuzukiMiyaura cross-coupling under the optimum reaction conditions established for catalysts 5, 6, 7 and 8 resulted in conversion to 
Table 1 Crystal data for 7

\begin{tabular}{|c|c|}
\hline Identification code & Complex 7 \\
\hline Empirical formula & $\mathrm{C}_{44} \mathrm{H}_{36} \mathrm{Cl}_{2} \mathrm{~N}_{4} \mathrm{Pd}$ \\
\hline Formula weight & 798.06 \\
\hline Temperature/K & $100(2)$ \\
\hline Crystal system & Triclinic \\
\hline Space group & $P-1$ \\
\hline$a / \AA$ & $6.7767(6)$ \\
\hline$b / \AA$ & $10.2586(9)$ \\
\hline$c / \AA$ & 13.5319(13) \\
\hline$\alpha /^{\circ}$ & $102.123(2)$ \\
\hline$\beta /^{\circ}$ & $98.442(2)$ \\
\hline$\gamma /{ }^{\circ}$ & $94.970(2)$ \\
\hline Volume $/ \AA^{3}$ & 903.05(14) \\
\hline$Z$ & 2 \\
\hline$\rho_{\text {calc. }} \mathrm{g} \mathrm{cm}^{-3}$ & 1.467 \\
\hline$\mu / \mathrm{mm}^{-1}$ & 0.700 \\
\hline$F(000)$ & 408.0 \\
\hline Crystal size $/ \mathrm{mm}^{3}$ & $0.364 \times 0.125 \times 0.12$ \\
\hline Radiation & $\operatorname{Mo} \mathrm{K} \alpha(\lambda=0.71073)$ \\
\hline $\begin{array}{l}2 \theta \text { range for data } \\
\text { collection }^{\circ}\end{array}$ & 4.092 to 56.714 \\
\hline Index ranges & $\begin{array}{l}-8 \leq h \leq 9,-13 \leq k \leq 13 \\
-18 \leq l \leq 18\end{array}$ \\
\hline Reflections collected & 12765 \\
\hline Independent reflections & $\begin{array}{l}4497\left[R_{\text {int }}=0.0346\right. \\
\left.R_{\text {sigma }}=0.0391\right]\end{array}$ \\
\hline Data/restraints/parameters & $4497 / 0 / 304$ \\
\hline Goodness-of-fit on $F^{2}$ & 1.079 \\
\hline Final $R$ indexes $[I \geq 2 \sigma(\mathrm{I})]$ & $\begin{array}{l}R_{1}=0.0287 \\
\mathrm{w} R_{2}=0.0675\end{array}$ \\
\hline Final $R$ indexes [all data] & $R_{1}=0.0316, \mathrm{w} R_{2}=0.0688$ \\
\hline Largest diff. peak/hole/e $\AA^{-3}$ & $0.46 /-0.31$ \\
\hline
\end{tabular}

biphenyl of only $62 \%$. This reduction in conversion demonstrates the stereoelectronic effect, caused by substituents on the pyrazole ring, on catalytic activity.

Carrying out the Suzuki-Miyaura cross-coupling reaction at $140{ }^{\circ} \mathrm{C}$ resulted in the formation of Pd-black when using 5, 6, 7 and 8 irrespective of the solvent used. Similar observations have been reported in literature for pyrazolyl palladium complexes, ${ }^{21,27}$ which were used in cross-coupling reactions carried out at temperatures higher than $65{ }^{\circ} \mathrm{C}$. However, carrying out the Suzuki-Miyaura cross-coupling reaction using 7 , at the established optimum reaction conditions, in toluene (using bromobenzene and phenylboronic acid as cross-coupling partners) with a large excess of mercury $(300: 1, \mathrm{Hg}: \mathrm{Pd})$ resulted in a drop in conversion from $98 \%$ to $84 \%$. This appreciably high conversion obtained using 7 , in the presence of mercury indicates in situ generated multi-species catalysts responsible for the catalysis. ${ }^{28-30}$

Similar observations were made when $\mathbf{8}$ was used as a precatalysts in the presence of metallic mercury, where conversion dropped from $81 \%$ to $77 \%$.

This is in contrast to other palladium catalyzed SuzukiMiyaura cross-coupling for which there was no aryl halide conversion after introducing mercury to the reaction mixture.

Generally phenyl bearing pre-catalysts 5 and 7 outperformed their tertiary butyl counterparts $\mathbf{6}$ and $\mathbf{8}$ over the course of these reactions. The presence of ester groups in $\mathbf{5}$ and $\mathbf{6}$ did not contribute any steric effect but lowered the electron-donation towards the palladium centre. This resulted in slightly lowered aryl halide conversions.

Suzuki-Miyaura cross-coupling reactions between various substrates using 5-8. Different boronic acids were coupled with various aryl halides using pre-catalysts $5-\mathbf{8}$ to evaluate the ability of the pre-catalysts to tolerate the presence of functional groups during the Suzuki-Miyaura cross-coupling reactions (Tables 2 and 3, Fig. 2). Using 4-bromotoluene and phenylboronic acid as coupling partners, resulted in high conversions to the respective biphenyls for pre-catalysts 5 and 7 ( $87 \%$ and $100 \%$ respectively) (Table 2, entries 5 and 7). Pre-catalysts 6 and 8 gave moderate conversions of $68 \%$ and $47 \%$ for the same substrates (Table 2, entries 6 and 8). This excellent conversion demonstrated by 5 and 7 could be as a result of increased electron-donation of the phenyl groups (by forming a conjugated system) with the pyrazole ring as compared to the tertiary butyl groups. Poor conversion for 6 (39\%) (Table 2, entry 10) and moderate conversion for 8 (70\%) (Table 2, entry 12$)$ could also be a result of the steric bulk of the tertiary butyl substituents. These bulky tertiary butyl groups may reduce interactions between the palladium centre and the substrates resulting in poor conversions. When the aryl halide (4-bromotoluene) was changed to the more sterically hindered 2-bromotoluene excellent conversion was obtained using 7 ( $98 \%)$. The other precatalysts gave conversions from $c a$. $40 \%$ to $70 \%$. This demonstrated the effect of the electron-withdrawing ester substituents on the phenyl rings of pre-catalysts 5 and 6 . Reducing the electron density from the palladium centre due to the presence of ester groups, resulted in suppressed conversions (Table 2).

Table 2 Effect of the presence of electron-donating groups on aryl halides $^{a}$

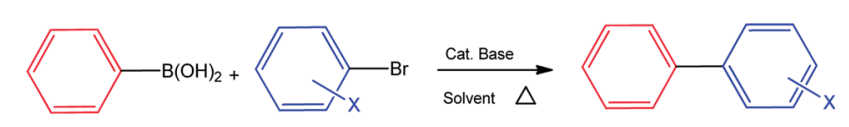

\begin{tabular}{|c|c|c|c|c|c|c|}
\hline Entry & Cat. & $\mathrm{X}$ & Conv. (\%) & $\begin{array}{l}\text { Selectivity } \\
(\%)\end{array}$ & TON & TOF $\left(\mathrm{h}^{-1}\right)$ \\
\hline 1 & 5 & $\mathrm{H}$ & 98 & 100 & 298 & 74 \\
\hline 2 & 6 & $\mathrm{H}$ & 87 & 100 & 263 & 66 \\
\hline 3 & 7 & $\mathrm{H}$ & 98 & 100 & 298 & 74 \\
\hline 4 & 8 & $\mathrm{H}$ & 81 & 100 & 245 & 61 \\
\hline 5 & 5 & $4-\mathrm{CH}_{3}$ & 87 & 100 & 262 & 66 \\
\hline 6 & 6 & $4-\mathrm{CH}_{3}$ & 68 & 99 & 206 & 51 \\
\hline 7 & 7 & $4-\mathrm{CH}_{3}$ & 100 & 99 & 303 & 76 \\
\hline 8 & 8 & $4-\mathrm{CH}_{3}$ & 47 & 97 & 141 & 35 \\
\hline 9 & 5 & $2-\mathrm{CH}_{3}$ & 64 & 100 & 195 & 49 \\
\hline 10 & 6 & $2-\mathrm{CH}_{3}$ & 39 & 99 & 117 & 29 \\
\hline 11 & 7 & $2-\mathrm{CH}_{3}$ & 98 & 99 & 298 & 75 \\
\hline 12 & 8 & $2-\mathrm{CH}_{3}$ & 70 & 97 & 212 & 53 \\
\hline
\end{tabular}

${ }^{a}$ Reactions carried out in toluene $(4.27 \mathrm{~mL})$ with $5 \mathrm{mmol}$ of aryl halide, $8 \mathrm{mmol}$ of phenyl boronic acid, $10 \mathrm{mmol}$ of $\mathrm{KOH}$ and $0.3 \mathrm{~mol} \% \mathrm{Pd}$ catalyst loading using $n$-decane as internal standard at $140{ }^{\circ} \mathrm{C}$ for $4 \mathrm{~h}$. Cat. = catalyst, Conv. = conversion. Average error estimates; 5 ( \pm 0.6210$), 6$ ( \pm 0.5919$), 7( \pm 0.4987), 8( \pm 0.4331)$. 
Table 3 Effect of the presence of electron-withdrawing groups on phenyl boronic acids ${ }^{a}$

\begin{tabular}{|c|c|c|c|c|c|c|c|}
\hline Entry & Cat. & $\mathrm{X}$ & $\mathrm{Y}$ & Conv. (\%) & $\begin{array}{l}\text { Selectivity } \\
(\%)\end{array}$ & TON & TOF $\left(\mathrm{h}^{-1}\right)$ \\
\hline 1 & 5 & $4-\mathrm{CHO}$ & $4-\mathrm{CH}_{3}$ & 53 & 97 & 162 & 40 \\
\hline 2 & 6 & 4-CHO & $4-\mathrm{CH}_{3}$ & 22 & 77 & 66 & 17 \\
\hline 3 & 7 & $4-\mathrm{CHO}$ & $4-\mathrm{CH}_{3}$ & 63 & 97 & 190 & 47 \\
\hline 4 & 8 & 4-CHO & $4-\mathrm{CH}_{3}$ & 21 & 93 & 63 & 16 \\
\hline 5 & 5 & 4-Cl & $4-\mathrm{CH}_{3}$ & 73 & 89 & 222 & 55 \\
\hline 6 & 6 & $4-\mathrm{Cl}$ & $4-\mathrm{CH}_{3}$ & 73 & 97 & 222 & 55 \\
\hline 7 & 7 & $4-\mathrm{Cl}$ & $4-\mathrm{CH}_{3}$ & 76 & 75 & 231 & 58 \\
\hline 8 & 8 & $4-\mathrm{Cl}$ & $4-\mathrm{CH}_{3}$ & 78 & 94 & 237 & 59 \\
\hline 9 & 5 & $4-\mathrm{Cl}$ & $\mathrm{H}$ & $63^{a}$ & 99 & 190 & 48 \\
\hline 10 & 6 & $4-\mathrm{Cl}$ & $\mathrm{H}$ & $79^{a}$ & 99 & 238 & 60 \\
\hline 11 & 7 & 4-Cl & $\mathrm{H}$ & $75^{a}$ & 99 & 227 & 57 \\
\hline 12 & 8 & 4-Cl & $\mathrm{H}$ & $62^{a}$ & 99 & 189 & 47 \\
\hline 13 & 5 & 4-Cl & 2-CN & $100^{a}$ & 100 & 303 & 76 \\
\hline 14 & 6 & $4-\mathrm{Cl}$ & 2-CN & $91^{a}$ & 79 & 276 & 69 \\
\hline 15 & 7 & 4-Cl & $2-\mathrm{CN}$ & $100^{a}$ & 100 & 303 & 76 \\
\hline 16 & 8 & 4-Cl & 2-CN & $100^{a}$ & 72 & 303 & 76 \\
\hline
\end{tabular}

${ }^{a}$ Reactions carried out in DMF (1.5 mL) with $1 \mathrm{mmol}$ of aryl halide, $1.6 \mathrm{mmol}$ of phenyl boronic acid, $2 \mathrm{mmol}$ of $\mathrm{KOH}$ and varying $0.3 \mathrm{~mol} \%$ Pd using $n$-decane as internal standard at $140{ }^{\circ} \mathrm{C}$ for $4 \mathrm{~h}$. Reactions carried out in toluene $(1.5 \mathrm{~mL})$. Cat. $=$ catalyst, Conv. $=$ conversion. Average error estimates; 5 ( \pm 0.5661$), 6$ ( \pm 0.4941$), 7$ ( \pm 0.5374$), 8( \pm 0.4821)$.

The influence of electron-withdrawing groups on the aryl halides was also investigated. When chlorobenzene was used as a coupling partner with phenylboronic acid, there were no conversions with any of the pre-catalysts. However, in the presence of an electron-withdrawing cyano group in 2-chlorobenzonitrile, we observed moderate conversions $(46 \%$ for 5 and $6,44 \%$ for 7 and $30 \%$ for 8 ) with all the pre-catalysts despite the steric limitations that might have been imposed by the nitrile group. This was probably as a result of the decrease in the bond dissociation energy of the $\mathrm{C}-\mathrm{Cl}$ bond caused by the presence of the cyano group. Due to the electron-withdrawing nature of the cyano group from the $\mathrm{C}-\mathrm{Cl}$ bond, the 2-chlorobenzonitrile is activated, thus the energy required in the formation of the oxidative addition intermediate is lowered.

A series of phenyl boronic acids with electron-withdrawing substituents were investigated in order to evaluate their effect on the Suzuki-Miyaura cross-coupling reactions. A typical example of such phenyl boronic acid that was investigated was 4-chlorophenyl boronic acid. With the presence of an electronwithdrawing group on the phenyl boronic acid, the results obtained were contrary to having the electron-withdrawing group on the aryl halide. For example, when phenyl boronic acid and bromobenzene were used as substrates (entry 3, Table 2) 98\% conversion was obtained for 7 . When 4 -chlorophenyl boronic acid and bromobenzene were used as substrates using 7 , we observed $75 \%$ conversion (entry 11, Table 3). Similar observations were also made for the other pre-catalysts. When 4chlorophenyl boronic acid and 4-bromo toluene were used as substrates, conversion obtained for 7 was $76 \%$ whereas $63 \%$ was obtained when 4-formylphenyl boronic acid and 4-bromo toluene were used. The presence of the lesser electronwithdrawing chloride resulted in increased aryl halide conversions as compared to the more electron-withdrawing formyl substituent (entries 1-8, Table 3). The low conversions with the phenyl boronic acid bearing electron-withdrawing group could be due to the decrease in the rate of the transmetallation step of the catalytic cycle as has been reported in literature. ${ }^{31}$

High conversions were observed for all four pre-catalysts when 2-bromobenzonitrile was coupled with 4-

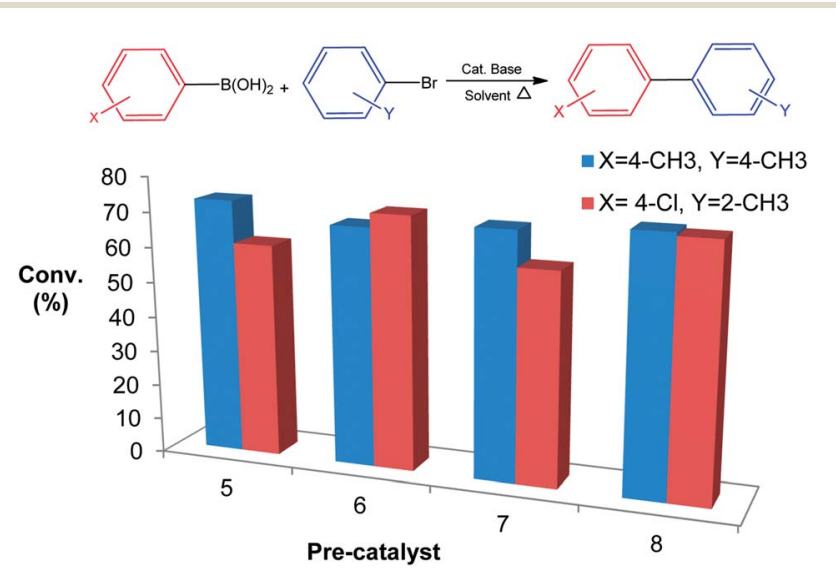

Fig. 2 Effect of steric bulk on phenyl boronic acids and aryl halides. Reactions carried out in DMF $(1.5 \mathrm{~mL})$ with $1 \mathrm{mmol}$ of aryl halide, $1.6 \mathrm{mmol}$ of phenyl boronic acid, $2 \mathrm{mmol}$ of $\mathrm{KOH}$ and varying $0.3 \mathrm{~mol} \%$ Pd using $n$-decane as internal standard at $140{ }^{\circ} \mathrm{C}$ for $4 \mathrm{~h}$. 
chlorophenylboronic acid. These high conversions were observed despite the presence of an electron-withdrawing chloro group on the phenyl boronic acid which would have been expected to reduce conversions (Table 3, entries 13-16). This was probably because the oxidative addition intermediate is expected to be formed relatively easily. Therefore, even if there is a decrease in the rate of transmetallation (with the presence of an electron-withdrawing group on the phenyl boronic acid), the reaction still gives excellent conversions.

We have observed that steric bulk around the carbon-boron bond or carbon-halide bond resulted in poor conversions. An example is the reaction between 2-nitroboronic acid or 3nitroboronic and bromobenzene. This reaction resulted in the loss of the boronic acid during coupling to form nitrobenzene which was confirmed by mass spectrometry. Using 4-formylboronic acid and 2-bromobenzene as substrates resulted in no conversion for all four pre-catalysts. These poor conversions could be as a result of steric hindrance or due to the electronwithdrawing effect of the formyl group on the phenyl boronic acids. When 4-bromotoluene was used instead of 2-bromobenzene as coupling partner with 4 -formylboronic acid, there was an increase in conversion possibly due to reduced steric hindrance (Table 3, entries 1-4). Similar observations were made when 4-chlorophenyl boronic acid was coupled with either 4-bromotoluene or 2-bromotoluene. Surprisingly, conversions for $\mathbf{6}$ and $\mathbf{8}$ were not significantly affected when an electron-withdrawing halide was present on the boronic acid as well as bulky group around the carbon bromide bonds (Fig. 2). This might indicate that carrying out the cross-coupling reaction in coordinating solvent (DMF) may result in a different catalytic pathway as compared to using a non-coordinating solvent such as toluene. This observation is also made where phenyl bearing pre-catalysts 5 and 7 were clearly outperformed by tertiary butyl counterparts 6 and 8 (Fig. 2) This suggests that catalytic activity is not solely dependent on the nature of the supporting ligands or resulting active species, but sometimes on the nature of the coupling reagents and/or solvent. In addition, with 8 as a pre-catalyst using $p$-tolylboronic acid and 4bromotoluene as cross-coupling partners (in DMF and metallic mercury), there was a decrease in conversion from $73 \%$ to $52 \%$. This slight drop in conversion suggests a cocktail of catalysts promoting the reaction. ${ }^{28,29}$

\section{Conclusions}

Four pyrazole containing ligands with ${ }^{t} \mathrm{Bu}$ and phenyl substituents on the pyrazole ring were prepared and characterized using NMR, mass spectrometry, infrared and single crystal X-ray diffraction (for 7). Four new bis(palladium) complexes were synthesized and characterized from these ligands. The complexes were evaluated for their catalytic activity in SuzukiMiyaura cross-coupling reactions. The pre-catalysts proved to be effective and the presence of steric bulk around the palladium centre did not inhibit conversions. In general, complexes bearing phenyl substituents performed better than those with ${ }^{t} \mathrm{Bu}$ substituents. This was likely as a result of the conjugated system the phenyl substituents formed with the pyrazolyl ring, resulting in increased electron-donation to the palladium. This could also be as a result of steric bulk by the ${ }^{t} \mathrm{Bu}$ substituents that inhibits interaction between the palladium centre and the substrates. The presence of ester groups on two of the precatalysts (5 and 6) resulted in slightly lowered conversions. Generally, all the pre-catalysts were selective towards the formation of the biaryl and no homo coupling products were observed. The presence of electron-withdrawing groups on the aryl halide served to increase conversions while an electronwithdrawing group on the phenyl boronic acid reduced conversion. Steric bulk around either the carbon-halide bond or the carbon-boron bond also lead to reduced conversions.

\section{Conflicts of interest}

There are no conflicts to declare.

\section{Acknowledgements}

We acknowledge the National Research Foundation of South Africa (NRF) (Grant Numbers: 95517 and 99269), Sasol and the University of Johannesburg Centre for Synthesis and Catalysis for financial support. We would also like to acknowledge $\mathrm{Mr}$ Gershon Amenuvor for his help in the solving of the crystal structure.

\section{References}

1 R. Martin and S. L. Buchwald, Acc. Chem. Res., 2008, 41, 1461-1473.

2 M. E. Hanhan, Appl. Organomet. Chem., 2008, 22, 270-275.

3 Y. Lai, Z. Zong, Y. Tang, W. Mo, N. Sun, B. Hu, Z. Shen, L. Jin, W. Sun and X. Hu, Beilstein J. Org. Chem., 2017, 13, 213-221. 4 S. Ghosh, A. S. Kumar and G. N. Mehta, Beilstein J. Org. Chem., 2010, 4, 4-7.

5 L. J. Goossen and B. Melzer, J. Org. Chem., 2007, 7473-7476. 6 Y. Yang, G. Li, Z. Song, X. Yang and P. Liu, Lett. Org. Chem., 2010, 7, 533-538.

7 A. R. Kapdi and I. J. S. Fairlamb, Chem. Soc. Rev., 2014, 43, 4751-4777.

8 F. K. Keter, S. Kanyanda, S. S. L. Lyantagaye, J. Darkwa, D. J. G. Rees and M. Meyer, Cancer Chemother. Pharmacol., 2008, 63, 127-138.

9 S. O. Ojwach and J. Darkwa, Inorg. Chim. Acta, 2010, 363, 1947-1964.

10 C. Chou, C. Yang, H. Syu and T. Kuo, J. Organomet. Chem., 2013, 745-746, 387-392.

11 Y. Zhang and G. Lavigne, Eur. J. Inorg. Chem., 2015, 20422050.

12 P. Štěpnička, M. Krupa, M. Lamač and I. Císařová, J. Organomet. Chem., 2009, 694, 2987-2993.

13 Y. Tang, Y. Zeng, Q. Hu, F. Huang and L. Jin, Adv. Synth. Catal., 2016, 358, 2642-2651.

14 I. Guzei, K. Li, G. Bikzhanova, J. Darkwa and S. Mapolie, Dalton Trans., 2003, 715-722.

15 S. Mohlala, M. Mohlala, I. A. Guzei, J. Darkwa and S. F. Mapolie, J. Mol. Catal. A: Chem., 2005, 241, 93. 
16 A. Budhai, B. Omondi, S. O. Ojwach, C. Obuah, E. Y. OseiTwum and J. Darkwa, Catal. Sci. Technol., 2013, 3, 3130.

17 N. M. Motsoane, I. A. Guzei and J. Darkwa, Z. Naturforsch., 2007, 62b, 323-330.

18 L. Yin and J. Liebscher, Chem. Rev., 2007, 107, 133-173.

19 A. N. J. Blok, P. H. M. Budzelaar and A. W. Gal, Organometallics, 2003, 22, 2564-2570.

20 D. Appavoo, B. Omondi, I. A. Guzei, J. L. Van Wyk, O. Zinyemba and J. Darkwa, Polyhedron, 2014, 69, 55-60.

21 A. Mukherjee and A. Sarkar, Tetrahedron Lett., 2005, 46, 1518.

22 G. K. Anderson, M. Lin, A. Sen and E. Gretz in Inorganic Syntheses, John Wiley \& Sons, Inc., Hoboken, NJ, USA, 2007, pp. 60-63.

23 G. Yang and R. G. Raptis, Inorg. Chim. Acta, 2003, 352, 98104.

24 F. Wu, H. Tong, K. Wang, X. Zhang and J. Zhang, J. Coord. Chem., 2016, 69, 1-5.
25 M. Jung, Y. Lee, M. Park, H. Kim, H. Kim, E. Lim, J. Tak, M. Sim, D. Lee, N. Park, W. K. Oh, Y. Hur, S. Kang and H. Lee, Bioorg. Med. Chem. Lett., 2007, 17, 4481-4486.

26 K. Li, J. Darkwa, I. A. Guzei and S. F. Mapolie, J. Organomet. Chem., 2002, 660, 108-115.

27 A. Mukherjee and A. Sarkar, ARKIVOC, 2003, 2003, 87-95.

28 A. S. Kashin and V. P. Ananikov, Russ. Chem. Rev., 2013, 82, 648-685.

29 D. B. Eremin and V. P. Ananikov, Coord. Chem. Rev., 2017, 346, 2-19.

30 Z. Li, C. Gelbaum, J. S. Fisk, B. Holden, A. Jaganathan, G. T. Whiteker, P. Pollet and C. L. Liotta, J. Org. Chem., 2016, 81, 8520-8529.

31 K. W. Quasdorf, A. Antoft-finch, P. Liu, A. L. Silberstein, A. Komaromi, T. Blackburn, S. D. Ramgren, K. N. Houk, V. Snieckus and N. K. Garg, J. Am. Chem. Soc., 2011, 133, 6352-6363. 